Fidei: Jurnal Teologi Sistematika dan Praktika, Vol. 4, No. 2, Des. 2021

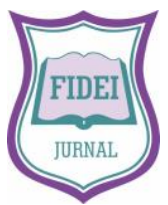

Fidei: Jurnal Teologi Sistematika dan Praktika

Terakreditasi No: 85/M/KPT/2020 (Sinta 4)

e-ISSN: $2621-8135$

http://www.stt-tawangmangu.ac.id/e-journal/index.php/fidei

Vol. 4 No.2 (Des. 2021) hlm: 315-325

p-ISSN: 2621-8151

Diterbitkan Oleh: Sekolah Tinggi Teologi Tawangmangu

DOI: https://doi.org/10.34081/fidei.v4i2.250

Resensi Buku

\title{
The Gospel of Judas dari Kodeks Tchacos
}

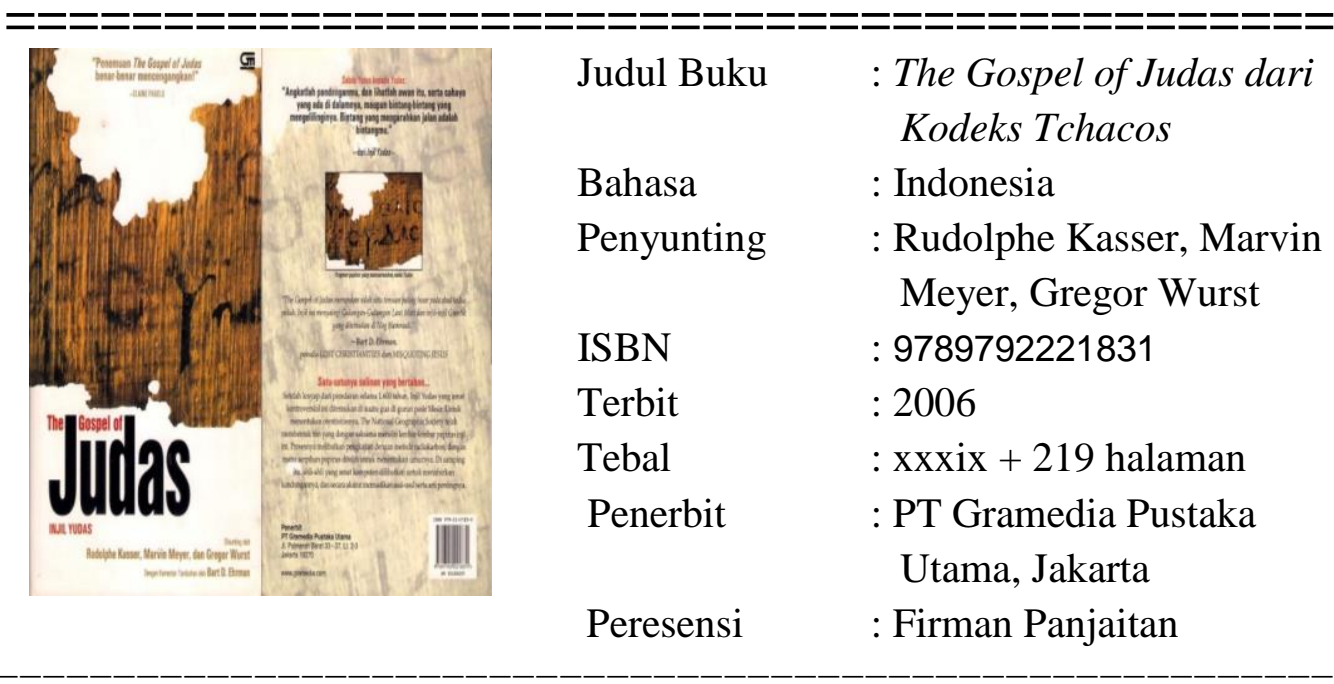

\section{Pendahuluan}

Di kalangan Kristen dikenal Empat Injil yang biasa disebut dengan Injil menurut Markus, Matius, Lukas dan Yohanes. Keempat Injil tersebut telah disahkan menjadi Kanon melalui proses kanonisasi, bersama dengan surat-surat Perjanjian Baru lainnya, yang memakan waktu yang sangat panjang. Dan dalam catatan sejarah, baru pada abad keempat terbentuklah kumpulan tulisan yang akhirnya dikenal sebagai Perjanjian Baru yang dikenal sekarang (hlm. xi). Dalam Keempat Injil yang dikenal, dicatat dan dikisahkan tentang Yesus Kristus yang mengalami kematian akibat ulah Yudas Iskariot, salah seorang murid Yesus yang mengkhianati-Nya. Kisah tentang hal ini telah berjalan sekian ribu tahun, karena sudah ditetapkan menjadi sebuah Kanon yang dipercaya sebagai Kitab Suci orang Kristen.

Akibat dari kanonisasi tersebut, maka para pemimpin umat seringkali menganjurkan agar tidak membaca beberapa tulisan yang memuat unsur-unsur 
ajaran yang tidak cocok dengan apa yang diberitakan oleh keempat4 Injil tersebut. Salah satunya adalah Injil Yudas, yang menurut Irenaeus, seorang Bapa Gereja, disebut sebagai salah satu ajaran sesat. Karena dalam Injil Yudas dikisahkan tentang Yesus yang tidak digambarkan seperti dalam Injil-Injil sebagai pribadi yang akan menanggung pendertiaan akibat kesediaan-Nya mengabdikan diri pada upaya penyelamatan manusia, melainkan sebagai pribadi yang mau melepaskan kemanusiaan dari dirinya (hlm. xv). Dan untuk mencapai keadaan itu, Yesus malah menugasi Yudas agar ikut terlibat untuk memungkinkan tercapainya tujuan dan arah yang Yesus mau. Dengan demikian, penggambaran tentang pribadi Yudas, dalam Injil Yudas, bukanlah merupakan penggambaran yang negatif, melainkan positif karena ia dilibatkan oleh Yesus untuk mengambil bagian dalam rencana Yesus untuk membebaskan dirinya dari ikatan kemanusiaannya yang dipandang sebagai penjara bagi jiwa Yesus. Dalam Naskah Injil Yudas juga ditampilkan tentang kemanusiaan Yesus yang dipandang sebagai selubung yang menghalangi jiwa dan perlu segera dilepaskan. Oleh sebab itu, Yesus menginginkan Yudas terlibat untuk memungkinkan tercapainya tujuan itu dengan cara menyerahkan Yesus kepada lawan-lawan-Nya

\section{Isi Injil Yudas}

Jika memeerhatikan dan mengamati Injil Yudas, maka sosok Yudas digambarkan sebagai pengkhianat Yesus tetapi sekaligus sebagai pahlawan dari Injil tersebut. Dalam Injil Yudas digambarkan bahwa Yesus berasal dari "alam yang tidak mengenal kematian" dan ini berarti mengakui bahwa Yesus adalah ilahi. Tetapi berbeda dengan Injil menurut Markus, Matius, Lukas dan Yohanes (selanjutnya penulis akan menggunakan istilah 'keempat Injil'), dalam Injil Yudas digambarkan bahwa hakikat tentang Yesus yang yang ilahi ini hanya dipahami oleh Yudas saja, sedangkan kesebelas murid lainnya sama sekali tidak memahami hal ini.

Injil Yudas memang mengakui bahwa Yesus adalah sosok penyelamat, namun perspektif yang dimaksud penyelamat di sini bukan karena wujud ragawi yang Yesus kenakan, melainkan karena Yesus mampu mewahyukan jiwa atau jati diri rohani yang mendiami jasad ragawinya, dan rumah Yesus yang sesungguhnya bukanlah "dunia bawah" yang tidak sempurna ini, melainkan ranah ilahi, alam keabadian yang penuh kecemerlangan cahaya dan kehidupan. Sehingga dalam peristiwa Yesus, kematian bukanlah dipandang sebagai sebuah 
tragedi sekaligus juga bukan sebuah kenistaan yang tak terelakkan demi menghasilkan pengampunan bagi dosa-dosa (hlm. xxv).

Injil Yudas seringkali menggambarkan Yesus yang tertawa. Yesus menertawakan kepicikan para murid-Nya dan absurditas kehidupan manusia. Bagi Injil Yudas, raga ini adalah absurd dan jalan untuk melepaskan diri dari keabsurditasan tersebut adalah kematian. Sehingga kematian Yesus dipandang sebagai bentuk pelepasan diri dari yang absurd (eksistensi ragawi) menuju pada keilahiannya yang hakiki. Dengan demikian pengkhianatan Yudas merupakan jalan terbaik bagi Yesus untuk menuju pada kematian sebagai jalan kelepasan dari penjara ragawi dan membebaskan diri sejatinya yang adalah roh ilahi. Jadi di sini Yudas ditempatkan sebagai sahabat yang paling mengerti tentang Yesus.

Menilik segala isi dan pemberitaan, Injil Yudas dapat diklasifikasikan sebagai Injil Gnostik, yaitu Injil yang menekankan pentingnya gnosis ("pengetahuan" mistik rahasia, ilmu gaib, pengetahuan mengenai Allah dan kesatuan esensial antara diri manusia dengan Allah). Jadi tidaklah mengherankan apabila tekanan utama dalam pemberitaan Injil Yudas ini adalah mengenai spiritulitas gnostik yang menegaskan bahwa dalam membangun hubungan dengan Allah manusia tidak perlu memakai perantara, karena dalam hakikatnya Allah adalah Roh dan Cahaya yang ada di dalam diri manusia.

Dalam sejarah gereja telah dicatat bahwa gerakan/aliran Gnostik ini sudah mendapat pertentangan yang keras dari pihak Gereja, dengan tuduhan bahwa ajaran Gnostik itu sesat. Namun Injil Yudas membalikkan padangan ini dengan mengatakan bahwa para pimpinan dan anggota Gereja resmi yang masih berada dalam proses pembentukannya justru menunjukkan perilaku yang tidak baik. Injil Yudas mengatakan bahwa apa yang dipahami oleh gereja mengenai Allah adalah adalah salah, karena Allah yang disembah gereja adalah "sesembahan" yang menjadi penguasa "dunia bawah" (yaitu dunia manusia yang tidak sempurna) dan mereka hidup dalam kebijaksanaan sesembahan dunia bawah tersebut.

Injil Yudas menegaskan bahwa kebenaran yang sesungguhnya bukan terletak dalam berita seperti yang dikisahkan oleh keempat Injil, karena kebenaran yang benar hanya dinyatakan oleh generasi Set (putra ketiga Adam) yang memiliki pengetahuan rahasia mengenai Tuhan Allah Yang Benar. Dan generasi Set ini dinyatakan sebagai kelompok manusia yang tercerahkan karena mengetahui setiap kebenaran rahasia dari Tuhan Allah Yang Benar.

Dalam bagian sentral pemberitaan Injil Yudas dikatakan bahwa Yesus adalah penyingkap kebenaran yang hakiki dan bukan sebagai penyelamat yang 
mati karena dosa-dosa dunia. Masalah mendasar kehidupan manusia bukanlah dosa, melainkan ketidaktahuan; dan jalan terbaik untuk mengatasi ketidaktahuan tersebut adalah pengetahuan (gnosis). Melalui pengetahuan, manusia akan diantar pada kesadaran mengenai kesatuan mereka dengan Tuhan Allah Yang Benar.

Pengetahuan tentang Tuhan Allah Yang Benar tertuang dalam pandangan kosmologi Injil Yudas, yang mengajarkan bahwa alam ilahi itu sangat transenden dan melalui proses emanasi dan penciptaan, angkasa raya menjadi penuh cahaya dan kemuliaan ilahi. Dewata Yang Tak Terbatas itu begitu tinggi, sehingga tidak dapat disebutkan dengan nama atau istilah apa pun, bahkan nama Tuhan saja belum bisa mewakili keberadaan Dewata Yang Tak Terbatas itu.

Berbeda dengan alam ilahi, alam bawah merupakan kancah bagi penguasa yang lebih rendah dan diciptakan oleh dewata pencipta yang disebut Nebro ("pemberontak") atau Yaldabaoth, yang jahat dan kejam. Inilah sebabnya kehidupan di dunia, yang merupakan alam bawah ini, senantiasa dipenuhi dengan masalah, karena pencipta dunia ini bukan Dewata Yang Tak Terbatas, yang berasal dari alam ilahi, melainkan "para bawahan" yang memiliki keterbatasan dan kekejaman.

Dengan menyadari hal tersebut, maka manusia harus membuka diri terhadap ajaran kebijaksanaan dan pengetahuan yang benar, sehingga manusia menyadari bahwa di dalam dirinya ada cahaya ilahi. Meskipun manusia hidup di dunia bawah yang penuh kegelapan, namun manusia memiliki sifat keabadian dari yang ilahi. Oleh sebab itu, jika Yesus dipandang sebagai Putra Ilahi, maka manusia pun adalah putra-putri Ilahi yang memiliki cahaya ilahi di dalam dirinya. Oleh sebab itu manusia harus menghidupi pengetahuan ilahi agar cahaya ilahi dalam dirinya dapat menyelamatkan manusia.

Cara pandang kosmologis Injil Yudas berbeda dengan keempat Injil, sehingga dalam Injil Yudas ditegaskan bahwa pengetahuan ilahi ini hanya dimiliki oleh Yudas, sedangkan kesebelas murid lainnya tidak memiliki. Itulah sebabnya mengapa Yudas harus mengkhianati Yesus, bukan karena Yudas adalah murid yang jahat, melainkan karena Yudas satu-satunya murid yang mengetahui bahwa Yesus harus mati demi kelepasan dirinya dari eksistensi ragawinya. Jadi, inti pesan yang hendak disampaikan Injil Yudas adalah pemahaman, wawasan, dan kesetiaan Yudas sebagai tolok ukut bagi siapa pun yang ingin menjadi murid Yesus. Yudas adalah "paradigma kemuridan", dan hanya Yudaslah yang melakukan persis apa yang diinginkan oleh Yesus (hlm. xxxi). 
Dalam Injil Yudas digambarkan bahwa Yudas tidak melakukan apa pun yang tidak dikehendaki oleh Yesus. Yudas tetap mendengarkan dan selalui setia kepada Yesus, dan bahkan Yudas dipandang sebagai murid kesayangan dan sahabat Yesus. Itulah sebabnya, pengkhianatan Yudas dipandang sebagai bentuk apa yang dikehendaki Yesus dan bukan dikarenakan keserakahan Yudas terhadap harta benda. Memang Yudas harus berkhianat untuk menggenapi apa yang menjadi kehendak Yesus.

Dalam Injil Yudas, Yesus menggaungkan paham Platonik yang menegaskan bahwa setiap pribadi memiliki bintangnya sendiri-sendiri, dan nasib manusia terkait dengan bintangnya tersebut. Yudas pun memiliki bintangnya sendiri. Dan menjelang akhir dari Injil Yudas, yaitu sebelum Yudas berubah wujud dan menjadi tercerahkan dalam lipuran awan cemerlang, dikisahkan bahwa Yudas disuruh Yesus untuk menatap ke langit, melihat bintang dan gemerlapnya permainan cahaya. Terdapat beberapa bintang di langit, tetapi bintang Yudas sungguh istimewa. Sebagaimana telah dikatakan oleh Yesus kepada Yudas, "Bintang yang mengarahkan jalan adalah bintangmu."

Injil Yudas merupakan Injil yang pemberitaannya sungguh berbeda dibanding dengan keempat Injil. Injil Yudas menempatkan Yudas pada posisi yang terhormat dibandingkan kesebelas murid lainnya, yang dipandang sama sekali tidak mengetahui apa-apa tentang Yesus. Dan ketidak tahuan kesebelas murid inilah yang menjadi bahan tertawaan dari Yesus.

\section{Apakah Injil Yudas Itu?}

Setelah melihat isi dari Injil Yudas, timbul pertanyaan sebenarnya asal muasal Injil Yudas itu dari mana? Apakah itu bagian dari penemuan-penemuan naskah kuno yang kemudian mengalami proses kanonisasi dalam menetapkan tulisan-tulisan untuk menjadi bagian dari Kitab Suci?

Dalam buku ini dijelaskan bahwa Injil Yudas baru ditemukan pada tahun 1970-an di Mesir Tengah, dan Injil Yudas merupakan naskah ketiga dalam bundelan papyrus yang disebut dengan Kodeks Tchacos. Naskah asli Injil Yudas ditulis dalam bahasa Yunani, tetapi teks dalam kodeks Tchacos ini telah disalin ke dalam bahasa Kopt. Secara rinci, Kodeks Tchacos adalah buku sepanjang enam puluh enam halaman dengan empat naskah, yaitu:

Pertama, halaman 1-9: Surat Petrus kepada Filipus (teksnya hampir sama dengan naskah kedua dari Kodeks VIII Nag Hammadi, dalam pustaka Nag Hammadi, dengan judul yang sama), Kedua, halaman 10-32, Jakobus (dengan teks yang hampir sama dengan naskah ketiga dari Kodeks $V$ dalam pustaka Nag 
Hammadi, yang diberi judul "Wahyu Yakobus" atau "Wahyu Pertama Yakobus"),

Ketiga, halaman 33-58: Injil Yudas (sebuah naskah yang sampai kini belum pernah diketahui, kendati judulnya disebut-sebut oleh Irenaeus dalam karyanya 'Melawan Kaum Bidah'), Keempat, halaman 59-66, suatu naskah yang sudah amat rusak, sedemikian rupa sampai judulnya hilang, kendati para sarjana telah bersepakat untuk menyebutnya Kitab Allogenes, berdasarkan nama tokoh utama dalam kitab tersebut (tetapi naskah ini tidak memiliki hubungan dengan naskah ketiga dari Kodeks XI dalam pustaka Nag Hammadi, yang berjudul Allogenes atau, 'Allogenes, Si Orang Asing') - (hlm. 43-44)

Naskah Kodeks Tchacos ini merupakan naskah gnostik, yang kemungkinan besar ditulis pada paroh pertama abad kempat Masehi, dan kemudian mengalami proses untuk diterjemahkan dengan cara yang berbelitbelit (dapat dibaca melalui tulisan Rudolphe Kasser, Kisah Kodeks Tchacos dan Injil Yudas, hlm. 41-76)

\section{Injil Yudas dan Kristianitas}

Kristianitas yang sudah establish mengalami penjungkirbalikan visi melalui kisah yang dipaparkan oleh Injil Yudas. Karena selama ini kekristenan memandang Yudas sebagai tokoh yang jahat, korup dan kerasukan setan; namun dalam Injil ini Yudas justru dipandang sebagai sahabat Yesus yang paling dekat. Satu-satunya teman Yesus yang memahami Yesus lebih baik daripada siapa pun dan yang menyerahkan Yesus kepada pejabat yang berwenang karena Yesus menghendaki dia (Yudas) melakukan hal itu. Semua ini dilakukan karena Yesus ingin membebaskan diri dari dunia materi yang bertentangan dengan Allah yang Benar dan kembali ke kediaman sorgawinya.

Injil Yudas, pada saat perkembangan awalnya, telah mendapat perlawanan dari seorang tokoh Bapa Gereja yang memerangi kaum Bidah (dari kelompok heresiologis = pemburu kaum bidah), yang bernama Irenaeus. Bagi Irenaeus, kelompok bidah yang paling berbahaya bagi ortodoksi Kristen adalah kaum gnostik; dan Injil Yudas merupakan produk dari kaum gnostik karena isi dan ciri yang tampak jelas dalam Injil Yudas adalah menunjukkan pada hasil kreasi dari kaum gnostik.

Melalui Injil Yudas, kaum gnostik mau mengatakan bahwa seseorang diselamatkan bukan karena beriman kepada yesus Kristus, atau karena melakukan perbuatan-perbuatan baik, melainkan karena mengetahui kebenaran, yaitu kebenaran mengenai dunia di mana manusia hidup, mengenai Allah yang 
benar dan khususnya mengenai siapa sebenarnya diri sejati manusia itu. Lebih lanjut kaum gnostik menjelaskan bahwa dunia kebenadaan bukan merupakan rumah bagi manusia. Manusia terperangkap dalam tubuh ragawi dan manusia perlu belajar bagaimana membebaskan diri dari perangkap tersebut. Dan bagi kaum gnostik Kristen, Yesus Kristus adalah pembawa pengetahuan itu dari atas. Dia mewahyukan kebenaran itu kepada para pengikut setia yang dekat dengannya, dan pengetahuan inilah yang bisa membebaskan mereka.

Mengapa pengetahuan tentang kebenaran dari atas itu penting untuk diketahui oleh manusia? Karena kaum gnostik memeercayai bahwa dunia yang menjadi tempat manusia hidup ini bukan merupakan ciptaan Allah Yang Mahatunggal Dan Benar. Namun demikian, meskipun dunia ini bukan merupakan ciptaan dari Yang Maha Benar, ada manusia yang berada di dalam dunia yang memiliki percikan ilahi di dalam dirinya, meskipun tidak semua. Oleh karena itu setiap manusia harus memiliki sarana untuk membebaskan diri dari belenggu ragawi ini, yaitu dengan cara memiliki pengetahuan (gnosis).

Yesus Kristus, oleh kaum gnostik, dipandang sebagai aeon (dewata) dari alam atas, dan dia bukan manusia dari darah dan daging, yang dilahirkan ke dalam dunia bawah yang merupakan ciptaan dari sesembahan manusia, yang bukan merupakan Allah yang sebenar-benarnya. Yesus datang dari atas dan hanya karena 'penampakannya' saja maka manusia mengenal dia dalam wujud manusia. Dia adalah Roh yang menampakkan diri dengan mengenakan jasad manusiawi, untuk mengajar manusia yang terpanggil (yaitu kaum gnostik yang memiliki percikan ilahi di dalam diri mereka) mengenai kebenaran-kebenaran rahasia yang mereka perlukan bagi keselamatan mereka (hlm. 89).

Karena dunia bawah ini bukan merupakan ciptaan dari Allah Yang Maha Benar, maka kaun gnostik memandang bahwa Allah dalam Perjanjian Lama bukanlah Allah yang benar, melainkan berupa dewata yang bebal. Jadi jika Perjanjian Lama mengisahkan tentang hal-hal yang bertentangan dengan kehendak Allah Perjanjian Lama, maka justru itulah yang sesungguhnya berasal dari Allah Yang Maha Benar. Dengan demikian, kaum gnostik menempatkan peristiwa-peristiwa dan tokoh-tokoh yang digambarkan sebagai yang jahat dalam Perjanjian Lama sebagai hal yang benar (misalnya: Kain dan peristiwa Sodom - Gomorah). Demikian juga dengan Yudas Iskariot, yang dipandang kaum gnostik sebagai orang yang justru melihat kebenaran dan memahami rahasia yang dipersyaratkan bagi keselamatan.

Dengan demikian tidaklah mengherankan apabila kaum gnostik, dengan pandangan yang jungkir balik ini, memandang kaum yang menjadi musuh 
Yesus, seperti yang digambarkan oleh keempat Injil, sebagai sekutunya yang paling besar. Bahkan Yudas dipandang sebagai pengikut Yesus yang utama, seseorang yang tindakannya harus diteladani, bukan dijauhi, karena dialah satusatunya orang yang oleh Yesus diberi pengetahuan rahasia yang diperlukan demi keselamatan.

Dalam pandangan yang menjungkirbalikkan keempat Injil, kaum Gnostik berpendapat bahwa kesebelas murid yang percaya kepada Allah dalam Perjanjian Lama dikatakan sebagai "pelayan kesesatan", sedangkan Yudas yang mengerti tentang kebenaran sejati adalah seorang pelayan yang paling besar, yang memberikan pelayanan kepada Yesus Kristus yaitu dengan cara menyerahkan Yesus untuk dieksekusi sehingga kesejatian diri ilahi Yesus dapat bebas dari perangkap dunia kebendaan ini. Hal ini memang pengkhianatan, tetapi pengkhianatan yang sudah direncanakan Yesus untuk dilakukan oleh Yudas. Yudaslah pahlawan bagi Yesus. Yudas melakukan semua itu karena Yudas sudah mengetahui kebenaran hakiki tersebut. Dalam hal ini Ysus mewahyukan kebenaran rahasia itu hanya kepada Yudas, pengikut dan sahabatnya yang paling setia, karena hanya Yudaslah yang mengetahui siapa Yesus sebenarnya. Dan Yudas bisa mengetahui siapa Yesus yang sebenarnya karena Yudas memiliki percikan olahi di dalam dirinya. Jadi dalam arti tertentu, Yudas memiliki kesamaan dengan Yesus; meskipun Yudas sendiri belum sampai pada pemahaman akan kebenaran rahasia yang paling dalam, seperti yang dipahami oleh Yesus.

Dalam upaya menjungkirbalikkan paham Kristianitas, Injil Yudas menghadirkan pandangannya tentang Allah. Injil Yudas menegaskan bahwa Allah Allah yang disembah oleh kesebelas murid, yang adalah Allah Perjanjian Lama, bukanlah Allah Yang Benar, yang menjadi sesembahan para murid. Dan itu berarti Yesus bukanlah Putra dari sesembahan mereka - itu sebabnya Yesus menertawakan kepercayaan kesebelas murid. Di sini jelas hendak menekankan bahwa para murid tidak tahu sama sekali tentang Yesus dan Allah Yang Benar. Hanya Yudaslah yang mengetahui hal ini.

Dalam pandangannya mengenai Kristus, Injil Yudas menegaskan bahwa Yesus bukan manusia biasa, karena Yesus adalah pribadi doketik, yaitu pribadi yang kelihatan manusia, hanya karena penampakannya saja. Yesus sebenarnya adalah pribadi yang berasal dari "alam yang tidak mengenal kematian, tempat kediaman Barbelo" dan (rupanya) setiap saat Yesus dapat saja berkunjung ke alam tersebut. Dan karena Yesus berasal dari alam yang tidak mengenal kematian, kemudian dia terperangkap di dalam dunia ini dalam tubuh 
ragawinya, maka dia memerlukan sebuah wujud kematian agar dapat terbebas dari penjara ragawi.

Yesus juga tidak memerlukan kebangkitan; karena kebangkitan itu tidak diperlukan sama sekali. Keselamatan bukan ditentukan oleh kebangkitan, melainkan keselamatan terjadi ketika manusia bisa membebaskan diri dari dunia kebendaan. Kebangkitan dari jazad yang sudah mati justu akan memasukkan Yesus ke dalam dunia yang diciptakan oleh dewata rendahan ini lagi.

Dari pandangan tentang Kristus dapat ditarik pemahaman tentang padangan kaum gnostik (Injil Yudas) mengenai keselamatan. Keselamatan adalah upaya untuk membebaskan diri dari dunia ini. Pembebasan itu bisa didapat melalui percikan ilahi yang ada di dalam diri manusia dan setelah mengalami kematian mereka akan kembali ke dalam alam asal mereka.

Injil Yudas juga menjungkirbalikkan pemahaman tentang pengikut Yesus. Dalam Injil Yudas digambarkan bahwa Yudas disingkirkan dari kelompok dua belas murid, sehingga Yesus menyebut Yudas sebagai "yang ketiga belas". Namun penyebutan "yang ketiga belas" ini merupakan penyebutan yang baik karena angka 13 merupakan angka keberuntungan. Kedua belas murid digambarkan sebagai orang-orang penyembah "allah pencipta" (Allah Perjanjian Lama), yang bukan Allah Yang Maha Benar. Ini berarti kedua belas murid adalah orang-orang yang sesat. Hanya Yudaslah murid yang mengetahui siapa sebenarnya Allah Yang Benar, sehingga ia diangkat menjadi murid sekaligus sahabat Yesus yang paling dekat. Dengan demikian, Injil Yudas benar-benar mau menjungkibalikkan paham Kristianitas.

\section{Tanggapan Kritis}

Dengan melihat serangan yang begitu kasar tehadap para pemimpin gereja dan keberadaan gereja, tidaklah mengherankan apabila Injil Yudas sama sekali tidak memiliki kesempatan untuk dimasukkan ke dalam kanon Perjanjian baru. Apalagi kalau diperhatikan secara seksama, banyak unsur dalam ajaran gnostik yang sebenarnya sangat bertentangan dengan nilai-nilai Kristiani. Memang gnostik kerapkali memakai istilah-istilah Kristen untuk mengembangkan gagasannya, di mana istilah itu mereka dapat dari Alkitab dan ajaran-ajaran gereja, akan tetapi gagasan yang mereka kembangkan ternyata sangat bertentangan dengan ajaran iman Kristen; antara lain:

Pertama, ajaran gnostik memisahkan antara Allah Perjanjian Lama dengan Allah Perjanjian baru. Ini merupakan ajaran yang perlu untuk dikritisi lebih lanjut lagi, karena Allah yang berkarya adalah Allah yang melampaui batas 
ruang dan waktu. Jika dibedakan antara Allah Perjanjian Lama dan Perjanjian Baru, maka akan diperoleh Allah yang terbatas dan tidak akan memiliki kekuasaan dalam batas, ruang dan waktu.

Kedua, ketika keselamatan dipandang sebagai pembebasan diri dari halhal yang bersifat ragawi dan bendawi, maka hal ini menjadi sebuah ajaran yang membingungkan. Manusia adalah satu kesatuan yang tak terpisahkan antara tubuh dan jiwa. Pernjanjian Lama mengatakan bahwa manusia adalah jiwa yang bertubuh dan/atau tubuh yang berjiwa. Jika tubuh itu jahat, apakah dapat menjadi tempat bagi jiwa yang baik/suci? Baik Perjanjian Lama dan Perjanjian Baru selalu memandang tubuh dan jiwa sebagai satu kesatuan ciptaan Tuhan yang baik. Bahkan ketika manusia diciptakan Allah sebagai gambar dan rupa Allah, maka yang dimaksud di sini adalah mengenai keberadaan manusia sebagai tubuh yang berjiwa. Dengan demikian tubuh bukanlah tempat kejahatan, meski memang merupakan bagian dari ketidakfanaan. Yesus sendiri sangat menghargai tubuh, sehingga kematian Yesus bukan bertujuan hendak membebaskan dirinya dari kungkungan penjara tubuh/raga, melainkan sudah menjadi bagian dari rencana Allah untuk member keselamatan kepada manusia secara utuh, yang keselamatan holistic yang mencakup keselamatan jiwa dan tubuh.

Hal yang paling perlu untuk dikritisi adalah mengenai istilah. Injil Yudas disebut sebagai Injil Yudas, bukan Injil Menurut Yudas. Ini berbeda dengan keempat Injil lain, yang disebut sebagai Injil menurut Markus, Matius, Lukas dan Yohanes. Jika Injil itu disebut dengan Injil Yudas, maka maksudnya adalah untuk menyatakan bahwa naskah ini adalah Injil mengenai Yudas. Dengan demikian Injil ini hendak bercerita tentang Yudas, bukan Yesus Kristus. Jika memang demikian, maka sudah selayaknya Injil ini tidak dimasukkan ke dalam kanon Perjanjian Baru karena berita yang disampaikan adalah mengenai Yudas Iskariot.

Tidaklah mengherankan apabila Injil Yudas penuh dengan pembelaan terhadap Yudas Iskariot, karena memang tujuan Injil ini ditulis adalah untuk menjelaskan segala sesuatu yang berkaitan dengan Yudas. Jadi jika Injil ini membicarakan kebaikan Yudas Iskariot, maka hal itu sah-sah saja, karena memang itu yang menjadi tujuan utamanya. Karena jika diartikan secara harfiah, maka Injil Yudas dapat diartikan dengan: Kabar gembira mengenai Yudas Iskariot; bukan mengenai Yesus Kristus.

Penulis melihat bahwa Kekristenan tidak perlu merasa khawatir dengan munculnya Injil Yudas ini, karena hal ini sama sekali tidak mengganggu Iman 
Kristen. Injil Yudas hanya dapat dipakai sebagai referensi untuk mengetahui perkembangan pandangan gnostik yang terjadi di awal abad pertama; di mana pandangan gnostik tersebut memang dapat dipandang sebagai pandangan yang hendak menentang ajaran Kekristenan. Namun di abad pertama itu juga ajaran gnostik sudah ditetapkan sebagai ajaran yang tidak sesuai dengan ajaran Kekristenan, sehingga dalam beberapa konsili sudah ditetapkan sebagai ajaran yang tidak perlu lagi diperhitungkan.

Kembali kepada Alkitab (back to the Bible) adalah jalan utama untuk menemukan kebenaran. Sama sepeti tiga slogan yang diungkapkan oleh Marthin Luther: Sola Fide (Hanya karena Iman), Sola Gratia (Hanya karena Anugerah), dan Sola Scriptura (Hanya karena Alkitab), maka keselamatan dalam Yesus Kristus dapat direngkuh.

\section{Daftar Pustaka}

Kasser, Rudolphe, Marvin Meyer, and Gregor Wurst. The Gospel of Judas Dari Kodeks Tchacos. Jakarta: PT Gramedia Pustaka Utama, 2006. 